\title{
A Two-country Model of High Skill Migration with Public Education
}

\author{
Research Center \\ ESSEC Working Paper 1301
}

2013

Claire Naiditch

Radu Vranceanu 


\title{
A TWO-COUNTRY MODEL OF HIGH SKILL MIGRATION WITH PUBLIC EDUCATION
}

\author{
Claire Naiditch* and Radu Vranceanu ${ }^{\dagger}$
}

\begin{abstract}
This paper proposes a two-country model of migration in a transferable skill sector, where workers' education is provided free of charge by governments. We study firstly the non-cooperative equilibrium where the poor country decides on the education level and the rich country decides on the quota of skilled migrants. Additional migration raises earnings prospects in the source country and attracts more talented people to that profession, what we refer to as the sector-specific brain gain effect. This game presents a single stable equilibrium with positive migration. Compared to the cooperative equilibrium, in the noncooperative equilibrium the poor country systematically under-invests in education. Whether migration is too strong or too weak depends on the size of the brain gain effect. Furthermore, the size of the welfare gain to be reaped by moving from non-cooperative to the cooperative organization of migration also depends on the strength of the sector-specific brain gain.
\end{abstract}

Keywords: High-skill migration, Brain-gain, Public education, Human capital, Government.

JEL Classification: F22; I25; H11

*Equippe, University of Lille 1. USTL - FSES, Cité scientifique, 59655 Villeneuve d'Ascq Cedex, France. Mail: claire.naiditch@univ-lille1.fr.

†ESSEC Business School and THEMA. BP50105, 95021 Cergy, France. Mail: vranceanu@essec.fr. 


\section{Introduction}

Slovenia is one of the smallest Eastern European countries, but also one of the wealthiest. There were 6.346 doctors and dentists working in the public health system in 2010. According to official estimates, additional 2.284 doctors would be needed to "secure the professional development of the system". Facing a shortage of capacity of the two faculties of medicine (Ljubljana and Maribor), the Slovenian government decided to "import doctors", mainly from the Eastern neighbor countries. In January 2011, the Parliament passed a law that reduced the procedure time for recognition of professional qualifications of foreign doctors from around one to two years to only a month. ${ }^{1}$

This anecdotal evidence is representative for an important trend in skilled migration. There are now between 192 and 216 million people living outside their place of birth (IOM, 2011; Ratha et al., 2011), which represents between 3 and 3.2 per cent of the world population. This means that roughly one of every thirty-five persons in the world is a migrant. Among these migrants, highly skilled workers represent an ever-growing share: looking at those living in OECD countries, their number increased by $70 \%$ during the 1990s; at the same time the number of low skilled immigrants increased by only $30 \%$. Massive migration of high-skill workers is often referred to as the "brain drain" effect, a concept that emphasizes the migration-driven erosion of human capital in countries that need it mostly. Several researchers have emphasized that migration of high-skill workers in "strategic occupations" such as health care and teaching could be extremely harmful for emerging countries, and this negative effect is enhanced when skilled migrants are trained in the source countries (Beine, Docquier and Oden-Defoort, 2011).

The dataset compiled by Docquier, Lowell and Marfouk (2009) provides emigration stocks and flows towards OECD countries from all the countries of the world at three educational levels. It shows that, over the last decades, the brain drain has increased in terms of stocks but not necessarily in terms of emigration rates. High income countries may provide more high-skill workers in magnitude, but higher emigration rates are found in middle-income countries. Data

\footnotetext{
1 Based on information provided by Slovenian Government at www.ukom.gov.si.
} 
provided by Docquier, Lowell and Marfouk (2009) do not differentiate between various professions and occupations. In their review of the economic literature on skilled migration, Docquier and Rapoport (2012) provide some case studies on notorious examples of brain drain: African medical doctors, European scientists and researchers and Indian IT specialists, showing that these highskill migrants differ in many respects but also have many things in common.

The economic literature on the brain drain mainly focuses on issues such as the determinants of skilled workers migration (see Docquier, Lohest and Marfouk, 2007; Ortega and Peri, 2009; Beine, Docquier and Ozden, 2011; Grogger and Hanson, 2011; Belot and Hatton, 2012) and the impact of skilled emigration on origin countries (see Docquier and Rapoport (2012) for an extensive literature review on this topic). In the late nineties, economists became more sensible to the argument according to which a country's pre-migration human capital stock could be endogenous to the prospect and realization of migration. A "New Economics of the Brain Gain" (Stark, 2005) emerged around the idea according to which, in presence of migration opportunities, individuals will invest more in education, thus raising the average human capital of educated individuals in the domestic country (see for instance Stark et al., 1997, 1998; Mountford, 1997; Beine et al., 2001, Beine, Docquier and Ozden, 2011; Stark and Dorn, 2012). Several empirical studies tend to corroborate these theoretical models (Beine et al., 2001, 2008; Beine, Docquier et Ozden, 2011, Chand and Clemens, 2008; Batista et al., 2012; Gibson and McKenzie, 2011; Cortes and Pan, 2012); they show that this brain gain effect exists, and that it is not negligible.

While the above mentioned theoretical literature has brought substantial insights to the process of human capital accumulation through private education, it is nevertheless important to notice that in many countries tertiary education is mostly financed through public funds. Individuals only have to finance a small part of the cost of their higher education; the main burden for students is thus their opportunity cost of postponing entering the job market. For instance, in 2009, OECD countries spend on average $6.2 \%$ of their GDP on educational institutions and tertiary education accounts for nearly one-quarter of this expenditure, or $1.6 \%$ of OECD countries' GDP. This represents on average US $\$ 13728$ per tertiary student. ${ }^{2}$ Expenditure per student by tertiary

2 Excluding activities peripheral to instruction such as research and development and ancillary services such 
institutions increased by 5 percentage points from 2000 to 2005 and by 9 percentage points over the 2005-09 period. In 2009, public funding accounts for $73 \%$ of all funds for tertiary educational institutions on average in OECD countries (it accounted for 78\% in 1995, 77\% in 2000 and $73 \%$ in 2005) (OECD, 2012; Figure 1). Among OECD countries, public funding accounts for more than $85 \%$ of all funding of higher education in European countries (Eurydice, 2011; Figure 2).

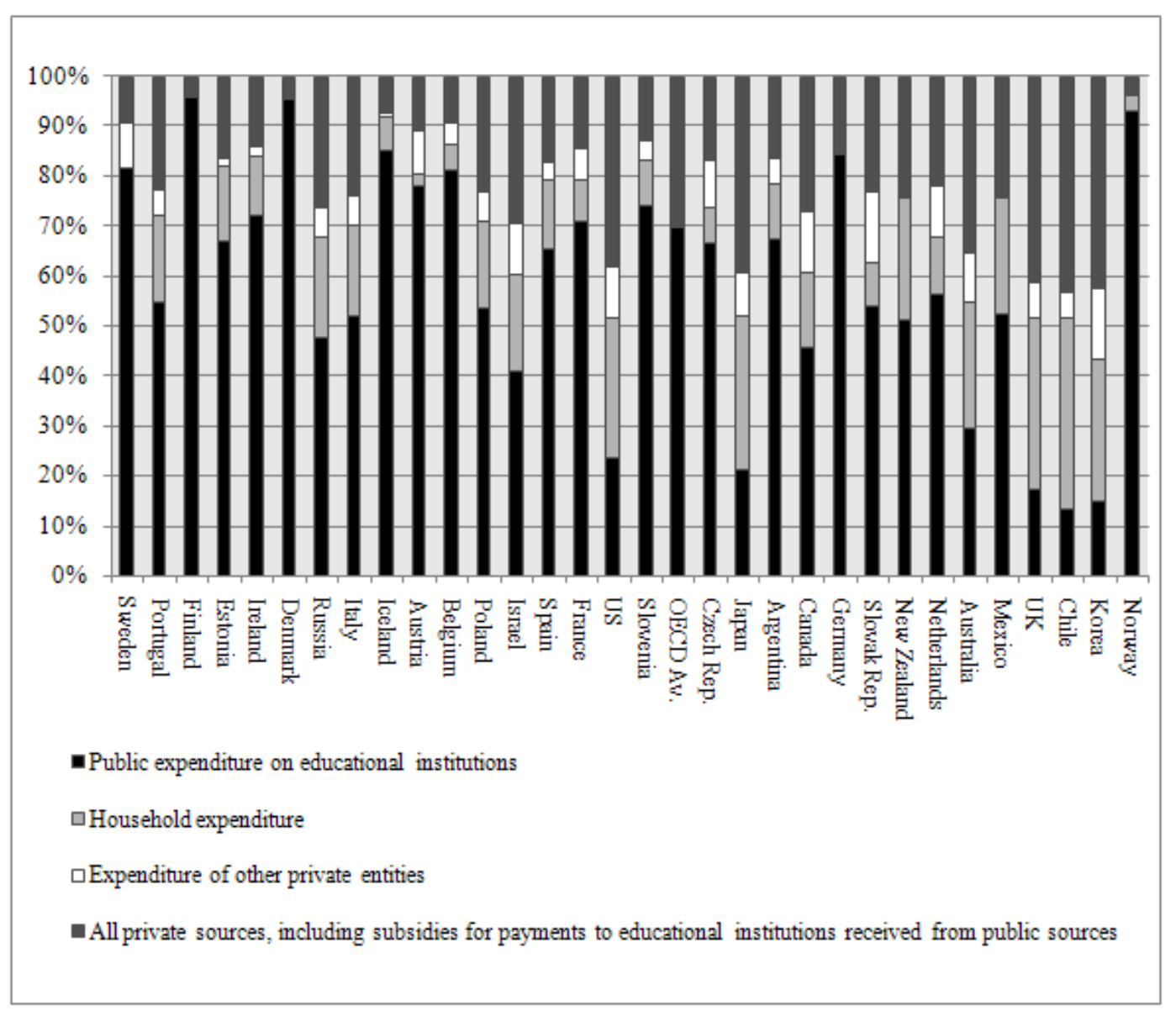

Figure 1: Distribution of expenditure in tertiary education in OECD countries, 2009. Source: OECD; Argentina: UNESCO Institute for Statistics (www.oecd.org/edu/eag2012).

Looking at developing countries and in particular at African countries, the picture is not so different. African countries steadily spent on average $0.78 \%$ of their GDP on tertiary institutions between 1995 and 2010. This represents approximately $20 \%$ of Africa's current public expenditure on education; this rate is comparable to the world average and higher than the corresponding rate of non-African developing countries (18\%). The public resources per student in tertiary education as welfare services to students, OECD countries annually spend on average US\$ 8944 per student at the tertiary level. 


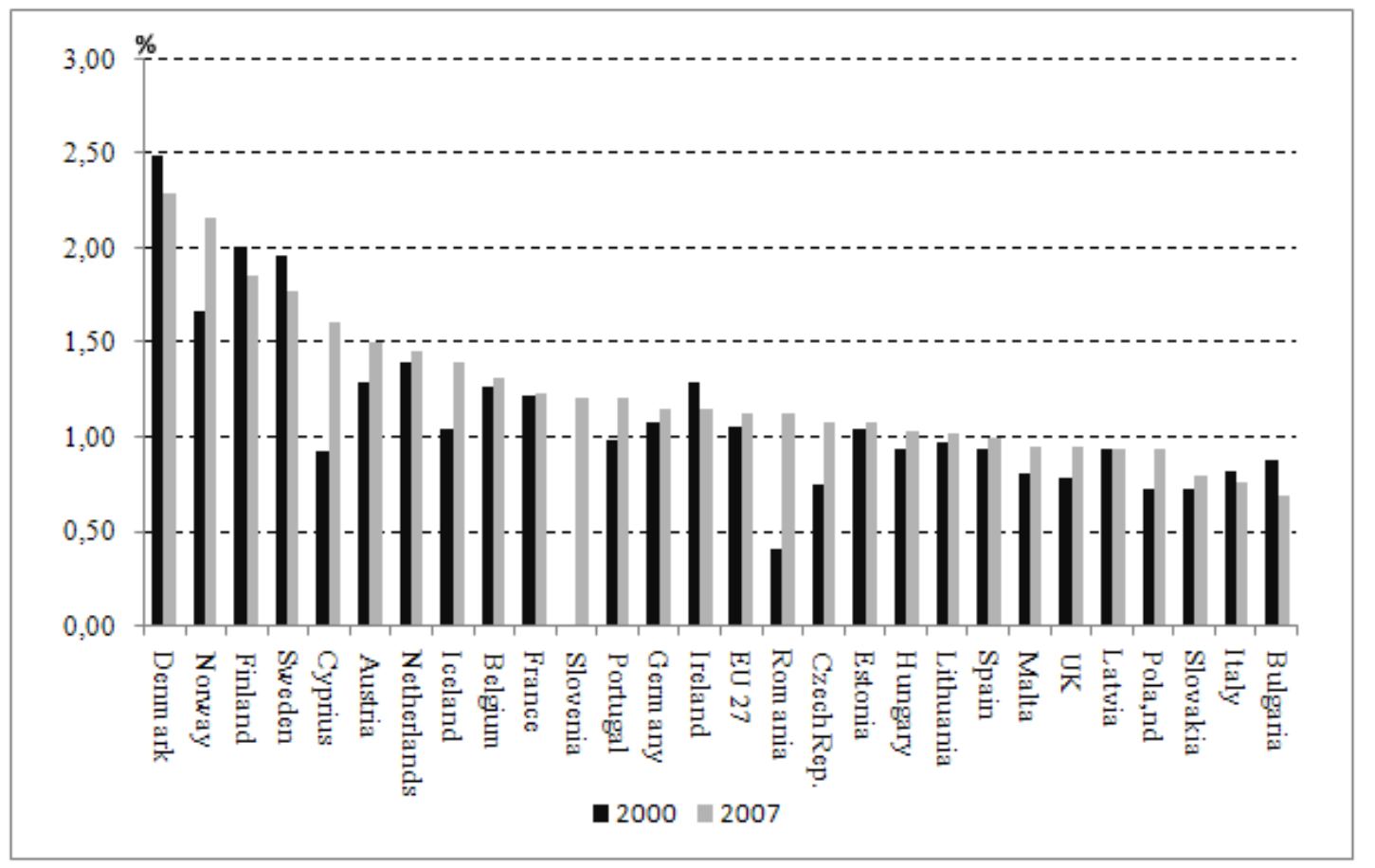

Figure 2: Total public expenditure on tertiary education in European countries.(as a percent of GDP).

Source: Eurostat, in Eurydice (2011).

have been decreasing over the last decade and amount to approximately US\$2 000 in 2006. Public funds represent approximately $75 \%$ of national expenditure on higher education (this figure is based on a sample of 18 countries only). The share contributed by households varies widely, from less than 10 percent in Mali, Chad, and the Republic of Congo to about 60 percent in Uganda and Guinea-Bissau. External assistance to higher education represents another important source of funds for tertiary education in Africa. Between 2002 and 2006, external assistance to higher education in Sub-Saharan Africa amounted to about US\$ 600 million annually. Note however that more than $70 \%$ of this amount was spent in donors' universities to compensate them for the cost of educating African students (World Bank, 2010).

This paper aims at analyzing skilled migration in a setup where (1) higher education is supplied by governments free of charge for individuals and (2) the opportunity to migrate attracts more talented persons to a given profession. The model is most relevant when applied to civil service sectors with high worker cross-border mobility (transferable skills), such as health care, higher education or fundamental research. In these sectors governments would commit to deliver a given 
volume of activity, and most often will sponsor the education of the civil servants.

Our sector-specific definition of the "brain gain" is close to that used by the above-mentioned literature: the prospect of migration raises the human capital of workers in the profession under scrutiny. Unlike other papers, we do not focus on individual decisions concerning the investment in education, but merely assume that Borjas' (1987) conditions for positive self-selection are fulfilled; thus, better earnings prospects in the profession open to migration (transferable skills) attracts better people from the rest of the economy (including the non-transferable skills sectors). In this respect, there is no overall brain gain, since the best people just move from the non-transferable to the transferable skills sector.

The problem is cast as a non-cooperative game between the source ("poor") country which chooses the education level per worker, taking as given the number of high-skill emigrants, and the host ("rich") country which decides on the number of highly skilled immigrants, taking as given their human capital. It will be shown that this game presents a single, stable Nash equilibrium with a positive number of migrants and a positive investment in education in the poor country. Changes in parameter values will be related to documented trends such as the development of emerging economies, or a higher price for capital in the wake of the Great Recession. The outcome of the non-cooperative equilibrium will then be compared to the cooperative solution. As it will be shown, the nature of the cooperative equilibrium depends to a large extent on the strength of the sector-specific brain gain effect.

To our knowledge, only a few migration studies have considered the case of public financing of education. Stark and Wang (2002) as well as Docquier, Faye and Pestieau (2008) analyze the appropriate policy mix between public subsidy for education and migration opportunities, when individuals finance part of their education cost and decide on their level of human capital, and origin countries' governments maximize a social welfare function. In a theoretical model, Poutvaara (2008) emphasizes the influence of the brain drain on the type of education publicly financed (internationally applicable or country-specific), when individuals choose their study effort. Our model is closer to the two-country model presented by Djajić et al. (2012). In their paper, the rich country decides on the duration of migrants' work permits and the poor country decides on the 
amount of public education per individual. Comparing the non-cooperative with the cooperative equilibrium where a social planner maximizes total welfare, they show that in the non-cooperative setting the poor country tends to under-invest in education; whether the duration of the work permit is too short or too long compared to the cooperative equilibrim level depends on the parameters. Besides a different policy transmission mechanism, what could be seen as an original contribution of our paper is the emphasis set on how migration is shifting the distribution of talents in the transferable skills sector.

The paper is organized as follows. The next section introduces the main assumptions of the model and studies the behavior of each country in the non-cooperative setup; in particular, we study the existence and stability properties of the equilibrium, as well as the local effects of the parameters on equilibrium variables. Section 3 analyzes the cooperative equilibrium in a bargaining framework. The last section presents the conclusion and some policy implications.

\section{The non-cooperative game}

There are two countries, referred to as the "Rich" and the "Poor" country, as we assume that there is a substantial gap between their development levels. Both need to produce a predetermined flow of a specific public service (for instance health care, fundamental research or higher education). Production of the public service requires effective labor services provided by qualified civil servants (respectively doctors, nurses, researchers or professors) and a constant amount of physical capital per civil servant. Effective labor services are proxied by the product between the number of workers and their average human capital. In turn, human capital depends on workers' education and on workers' talent, heterogeneously distributed in the population of workers attracted to that profession. Education of civil servants is provided for by the government, free of charge for the individuals. We focus on professions where skills are transferable from one country to another. For instance, a researcher in nuclear physics trained in India can find an equivalent job in the US. On the opposite, an Indian judge, trained in specific Indian law, cannot easily work as a judge in the US.

Civil servants trained in the poor country migrate to the rich country provided that they get a 
work permit. Implicitly, we make the standard assumption according to which, for civil servants in the poor country, utility from working in the rich country is higher than the cost of migrating, and the net utility when migrating is higher than the utility when staying. The rich country decides on the number of work permits.

Both countries aim at minimizing the investment cost of delivering the required amount of public services.

In a first step, the problem is studied as a non-cooperative game between the two countries. More precisely, the rich country decides on the number of migrants it is willing to accept (work permits delivered), taking as given their human capital. The poor country will choose the education level per worker, taking as given the number of migrants. In the Cournot-Nash equilibrium, each country adopts its best strategy, given that the other country follows its best strategy.

\subsection{The "poor" country}

The poor country must provide a predetermined amount of a specific public service (health care for instance), denoted by $Y_{P}$. Following an approach introduced by the efficiency wage theory (Solow, 1979), we assume that the production function can be written:

$$
Y=F_{P}(N q)
$$

where $F_{P}()$ has the standard neoclassical properties, and $N q$ is the volume of effective labor services, delivered by $N$ civil servants (e.g. doctors) having an average human capital $q$. Production also requires a fixed amount of physical capital per employed worker (such as real estate, various equipment, computers, etc.).

We denote human capital of individual $i$ by $q_{i}=q\left(e, t_{i}\right)$, where $e$ is the education received by an individual and $t_{i}$ is the individual's talent or ability to transform education in valuable skills for "real work". We admit that $q_{i}=e t_{i}$.

The total number of young people who graduate in the required profession is $N+M$, where $N$ are those who will get a job at home and $M$ are those who will migrate. The public education budget thus is $E \equiv e(N+M)$. Following Beine et al. (2001), we consider that the ability to migrate depends on some characteristic that is independent of acquired human capital (family 
wealth, the network of friends, etc.). Thus migrants are drawn at random from the population of graduates; the average human capital of the migrants will thus be identical to the average human capital of the left-home persons. ${ }^{3}$

We admit that individuals attracted by the perspective of getting a job as a civil servant in the profession with migration opportunities are heterogenous with respect to talent $t$. To keep the analysis as simple as possible, we assume that $t$ is uniformly distributed on the interval $\left[0, t^{\text {sup }}\right]$, where $t^{\text {sup }}$ denotes the upper bound of the talent distribution.

Better prospects of migration raise the expected wage of workers that would train for that profession. ${ }^{4}$ We make the somehow trivial assumption according to which a higher expected wage attracts to that profession "the more able" persons from the rest of the economy (including from the non-transferable skills sector). The precise conditions for such positive self-selection to occur were stated by Borjas (1987) building on the classical paper by Roy (1951). In particular, the wage distribution in the transferable skills sector should be larger than in the rest of the economy, which is consistent with the higher wage abroad hypothesis, and the correlation of talents in the two sectors should be large enough. Taking a macroeconomic perspective that simplifies the underlying process, we further consider that the upper bound of the talent distribution in the transferable skills sector is positively related to the number of migrants $M$. To keep the analysis as simple as possible, we assume that $t^{\text {sup }}$ is a linear function in $M, t^{\text {sup }}=t_{0}+\lambda M$, where $\lambda>0$ is the sensitivity of talent to $M$, and $t_{0}>0$.

In this paper we will refer to "the sector-specific brain gain effect" as the positive impact of migration prospect on the talent of workers attracted to the transferable skills sector (the parameter $\lambda$ captures the "strength" of the effect). As mentioned in the introduction, there is no scope for "global" brain gain, since good people attracted to the transferable skills sector actually leave from the other sectors of the economy.

\footnotetext{
3 Other papers (Chiquiar and Hanson, 2005; McKenzie, Stillman and Gibson, 2010; Cortes and Pan, 2012) consider the issue of the self-selection of migrants, which implies that migrants are necessarily those individuals at the higher end of the human capital distribution. Probably, in real life, human capital has an impact on the realization of migration, but whether this impact is strong as compared to other factors is a question still open to debate.

4 The expected wage of a candidate to education in that sector being $\left(N w_{P}+M w_{R}\right) /(N+M)$, where $w_{P}\left(w_{R}\right)$ is the wage in the poor (rich) country, with $w_{R}>w_{P}$.
} 
The average talent is: $t_{a v}=0.5\left(t_{0}+\lambda M\right)$. In turn, the average human capital of individuals trained in the poor country can be written:

$$
q=0.5\left(t_{0}+\lambda M\right) e
$$

Since we assumed that migrants self-select on a different criterion than talent, it turns out that the average human capital of migrants and of the left-home persons is identical.

Given the production function (1), the amount of labor services required to achieve the production target $Y_{P}$ is:

$$
N q=F_{P}^{-1}\left(Y_{P}\right)
$$

Replacing $q$ by expression (2), we get:

$$
0.5 N\left(t_{0}+\lambda M\right) e=F_{P}^{-1}\left(Y_{P}\right)
$$

The former equation indicates the pairs $(N, e)$ the poor country can choose in order to reach his service target, given $M$ decided by the rich country. For instance, we can write:

$$
N=\frac{\psi^{2}}{e\left(t_{0}+\lambda M\right)} \text { with } \psi=\sqrt{2 F_{P}^{-1}\left(Y_{P}\right)}
$$

or, alternatively, $e$ as a function of $N$.

We assume that the poor country aims at achieving the service target $Y_{P}$ with the lowest investment cost in human and physical capital. The investment cost of obtaining any service target is:

$$
C_{P}=c N+e(M+N)
$$

where $c$ is the (constant) per-capita cost of the physical capital required to equip domestic workers, and $e$ is the per-capita education cost, that applies to both future migrants and left-home persons.

So the decision problem of the poor country government is:

$$
\left\{\begin{array}{l}
\min _{N, e}\left\{C_{P}=c N+e(M+N)\right\} \\
\text { with: } N=\frac{\psi^{2}}{e\left(t_{0}+\lambda M\right)}
\end{array}\right.
$$

In order to solve it, we introduce the constraint in the objective:

$$
C_{P}=\frac{(c+e)}{e} \frac{\psi^{2}}{\left(t_{0}+\lambda M\right)}+e M
$$


and we look for the minimum of $C_{P}$. The FOC $d C_{P} / d e=0$ leads to the optimal education level (denoted by $e_{P}$ ):

$$
e_{P}=\frac{\psi \sqrt{c}}{\sqrt{M\left(t_{0}+\lambda M\right)}}
$$

The relationship between $e_{P}$ and $M$ is the best response function of the poor country, indicating the optimal education level given the quota of migrants chosen by the rich country. We have $\lim _{M \rightarrow 0} e_{P}=+\infty, \lim _{M \rightarrow+\infty} e_{P}=0, \frac{d e_{P}}{d M}<0$ and $\frac{d^{2} e_{P}}{d M^{2}}>0$. We will alternatively refer to the $e_{P}=e_{P}(M)$ function as the $P P^{\prime}$ curve, as represented in Figure 3. We can further check that $d^{2} C_{P} / d e^{2}>0$, the optimal solution corresponds to a minimum of the cost function.

Expression (9) indicates that $e_{P}$ is decreasing in $M$. Indeed, if the rich country raises the quota of migrants $(d M>0)$, all things equal, the cost of producing the service $Y_{P}$ increases. The rest of the story depends on the strength of the sector-specific brain gain effect. If the brain gain effect is weak enough, then the productivity gain is modest; facing a higher total investment in education, the poor country might want to reduce the education level per worker and hire more locals. If the brain gain effect is strong, then, for a given $d M>0$, there is a powerful productivity gain. The poor country can achieve the same level of service while reducing its investment in education, even if this will offset to some extent the first effect. ${ }^{5}$

Notice that changes in parameters shift the $P P^{\prime}$ curve as indicated by the arrows in Figure 3. Indeed, from expression (9), it can be seen that: $\frac{\partial e_{P}}{\partial \psi}>0, \frac{\partial e_{P}}{\partial t_{0}}<0, \frac{\partial e_{P}}{\partial c}>0$ and $\frac{\partial e_{P}}{\partial \lambda}<0$. In line with intuitive reasoning, the required (optimal) education level increases if the production target is raised, or if talent is "scarcer". The required education level also increases if the cost of equipping a worker increases; in this case, it is better to employ less staff, but each of them must be more productive thanks to a better training.

Introducing equation (9) in equation (5), we can also determine the optimal number of staff needed at home for the production of the public service, $N_{P}$ :

$$
N_{P}=\frac{\psi}{\sqrt{c}} \sqrt{\frac{M}{t_{0}+\lambda M}} .
$$

where $N_{P}$ is an increasing function in $M$.

\footnotetext{
${ }^{5}$ In section 3 we move beyond this intuitive analysis and study more in depth the cost response to changes in $e$ and $M$ (depending on $\lambda$ ).
} 


\subsection{The "rich" country}

As in the poor country, the rich country government must provide a given amount of public services $Y_{R}$, at the lowest investment cost. At difference with the poor country, the rich country can use either locals trained locally, or migrants trained in the poor country. While the rich country can decide on the number of work permits $M$, it takes the education level of migrants as given. Production of the public service also requires a fixed amount of physical capital per worker.

We have denoted by $M$ the migrants, and by $q$ their average human capital. Denoting by $Z$ the number of locals and by $\theta$ their average human capital (exogenously given), the production function is:

$$
Y=F_{R}(Z \theta, M q) .
$$

The production function must allow for partial complementarity and partial substitution between the two types of effective labor services, mostly because of coordination problems. For instance, when the group is dominated by a category of persons (be them locals or foreigners), it is beneficial to integrate a different one, since it comes with complementary skills, but this will affect the internal cohesion of the group. It is also reasonable to assume that the production function features constant returns to scale. A convenient form that has these properties and also allows to reach analytical solutions is the Cobb-Douglas function:

$$
Y=(Z \theta)^{0.5}(M q)^{0.5} .
$$

For the rich country, the education cost of a migrant is assumed to be nil. Let $w$ be the cost of training a domestic worker, and $c$ be the cost of physical capital per worker (for simplicity, it is assumed to be the same as in the poor country). We denote the relative cost of employing a worker trained in the rich country compared to a worker trained in the poor country by $\sigma=$ $\frac{w+c}{c}=\frac{w}{c}+1>1$.

The investment $\operatorname{cost} C_{R}$, whatever the production target, can be written as:

$$
C_{R}=(w+c) Z+c M .
$$


The rich country decision problem is:

$$
\left\{\begin{array}{l}
\min _{Z, M}\left\{C_{R}=(w+c) Z+c M\right\} \\
\text { with: }(Z \theta)^{0.5}(M q)^{0.5}=Y_{R} \\
\text { with: } q=0.5\left(t_{0}+\lambda M\right) e
\end{array}\right.
$$

Note that the rich country has no impact on the education level $e$, but can have an impact on the human capital of the migrants, anticipating that higher migration opportunities should attract better people to that profession in the poor country.

Given the production function (12) and the expression of $q$ (eq. 2), the amount of native labor services required to achieve the production target $Y_{R}$ is:

$$
Z \theta=\frac{2\left(Y_{R}\right)^{2}}{e M\left(t_{0}+\lambda M\right)} .
$$

The former equation indicates the pairs $(Z, M)$ the rich country can choose in order to reach his service target, given the education level $e$ decided by the poor country. For instance, we can write:

$$
Z=\frac{2\left(Y_{R}\right)^{2}}{e \theta M\left(t_{0}+\lambda M\right)}
$$

or, alternatively, $M$ as a function of $Z$.

So the decision problem of the rich country government can be re-written as:

$$
\min _{M}\left\{C_{R}(M)=\frac{2(w+c)\left(Y_{R}\right)^{2}}{e \theta M\left(t_{0}+\lambda M\right)}+c M\right\} .
$$

The FOC $d C_{R}(M) / d M=0$ leads to the implicit definition of the optimal migration level (denoted by $\left.M_{R}\right)$, given $e$ and the various parameters:

$$
\frac{\left[M_{R}\left(t_{0}+\lambda M_{R}\right)\right]^{2}}{\left(0.5 t_{0}+\lambda M_{R}\right)}=\frac{1}{e} \frac{\left(2 Y_{R}\right)^{2} \sigma}{\theta} .
$$

We define:

$$
\begin{aligned}
G(M) & =\frac{\left[M\left(t_{0}+\lambda M\right)\right]^{2}}{0.5 t_{0}+\lambda M} \\
b & =\left(2 Y_{R}\right)^{2} \frac{\sigma}{\theta}
\end{aligned}
$$

and we get the implicit definition of $M_{R}$ :

$$
G\left(M_{R}\right)=\frac{b}{e} .
$$

We can state: 
Proposition 1 There is a single $M_{R}$, such that $G\left(M_{R}\right)=\frac{b}{e}$.

Proof. It can be seen that $G(0)=0$ and $\lim _{M \rightarrow+\infty} G(M)=+\infty$. Furthermore, $G(M)$ is a monotonously increasing function in $M$ :

$$
G^{\prime}(M)=\frac{M\left(t_{0}+\lambda M\right)}{\left(0.5 t_{0}+\lambda M\right)^{2}}\left[3 \lambda^{2} M^{2}+3 t_{0} \lambda M+\left(t_{0}\right)^{2}\right]>0, \forall M>0
$$

Since $\frac{b}{e}>0, \exists ! M_{R}>0$ such that $G\left(M_{R}\right)=\frac{b}{e}$.

Proposition $2 M_{R}$ is a decreasing function in e.

Proof. By differentiating equation (21) we get:

$$
\begin{aligned}
G^{\prime}\left(M_{R}\right) d M_{R} & =-\frac{b}{e^{2}} d e \\
\frac{d M_{R}}{d e} & =-\frac{b}{e^{2} G^{\prime}\left(M_{R}\right)}<0
\end{aligned}
$$

The optimal quota of migrants $M_{R}$ is a decreasing function in the education level $e$ such as decided by the poor country.

Indeed, if $e$ decreases, all things equal the rich country should bring in more migrants to provide the required service level. Allowing for additional migration would raise the average quality of these migrants, which would partially offset the first direct effect, without canceling it.

The relationship between $M_{R}$ and $e$ can be interpreted as the best response function of the rich country, when the poor country decides on the level of $e$.

Since $M_{R}(e)$ is monotonous on the interval $] 0 ;+\infty\left[\right.$, it admits a reciprocal $e_{R}(M)$ that we will refer to as the $R R^{\prime}$ curve (represented in Figure 3):

$$
e_{R}(M)=\frac{b}{G(M)}=b \frac{0.5 t_{0}+\lambda M}{M^{2}\left(t_{0}+\lambda M\right)^{2}}
$$

The function $e_{R}(M)$ is decreasing in $M$ and convex, with $\lim _{M \rightarrow 0} e_{R}=+\infty, \lim _{M \rightarrow+\infty} e_{R}=0, \frac{d e_{R}}{d M}<0$ and $\frac{d^{2} e_{R}}{d M^{2}}>0$.

Changes in parameters shift the $R R^{\prime}$ relationship as indicated by the arrows in Figure 3. Since $b=\frac{\left(2 Y_{R}\right)^{2}}{\theta}\left(1+\frac{w}{c}\right)$, it turns out that $\frac{\partial e_{R}}{\partial Y_{R}}>0, \frac{\partial e_{R}}{\partial w}>0, \frac{\partial e_{R}}{\partial c}<0$ and $\frac{\partial e_{R}}{\partial \theta}<0$. We also can show that $\frac{\partial e_{R}}{\partial t_{0}}=-\frac{b M\left(0.5 t_{0}+1,5 \lambda M\right)}{\left[M\left(t_{0}+\lambda M\right)\right]^{3}}<0$ and $\frac{\partial e_{R}}{\partial \lambda}=-\frac{b \lambda}{\left(t_{0}+\lambda M\right)^{3}}<0$. 
Eventually, the optimal number of locals $Z_{R}$ can be determined by introducing $M_{R}$ in equation (16).

\subsection{The Nash Equilibrium}

A Cournot-Nash equilibrium of this game is a pair $\left(e^{*}, M^{*}\right)$ satisfying simultaneously Equation (9) and Equation (25). If such a pair exists, the poor country decides on the optimal education level taking as given the quota of migrants decided by the rich country, and the rich country optimally decides on the number of migrants taking as given their education level such as chosen by the poor country. The total numbers of workers trained by the poor country and of local workers employed by the rich country are also obtained as equilibrium values (Equations 10 and 16).

The equilibrium condition is:

$$
\begin{aligned}
e_{P}(M) & =e_{R}(M) \\
\frac{\psi \sqrt{c}}{\sqrt{M\left(t_{0}+\lambda M\right)}} & =\frac{b\left(0.5 t_{0}+\lambda M\right)}{\left[M\left(t_{0}+\lambda M\right)\right]^{2}} .
\end{aligned}
$$

We define:

$$
J(M)=\frac{\left[M\left(t_{0}+\lambda M\right)\right]^{3}}{\left(0.5 t_{0}+\lambda M\right)^{2}}
$$

After some calculations, the equilibrium condition (26) can be written as:

$$
J(M)=\frac{1}{c}\left(\frac{b}{\psi}\right)^{2}
$$

where we recall that $b=\frac{\left(2 Y_{R}\right)^{2}}{\theta}\left(1+\frac{w}{c}\right)$ and $\psi=\sqrt{2 F_{P}^{-1}\left(Y_{P}\right)}$. This condition implicitly defines the equilibrium number of migrants, denoted by $M^{*}$.

Proposition 3 There is a single, positive, finite number of migrants satisfying the Cournot-Nash equilibrium condition (29).

Proof. It can be seen that $J(0)=0$ and $\lim _{M \rightarrow+\infty} J(M)=+\infty$. The function $J(M)$ is monotonously increasing in $M$ :

$$
J^{\prime}(M)=\frac{\left[M\left(t_{0}+\lambda M\right)\right]^{2}\left[\left(t_{0}+2 \lambda M\right)^{2}+0.5\left(t_{0}\right)^{2}\right]}{\left(0.5 t_{0}+\lambda M\right)^{3}}>0, \forall M>0 .
$$

Since $\frac{1}{c}\left(\frac{b}{\psi}\right)^{2}>0$, thus $\exists ! M^{*}>0$ such that $J\left(M^{*}\right)=\frac{1}{c}\left(\frac{b}{\psi}\right)^{2}$.

The fact that the solution to Equation (29) is single tells us that the $P P^{\prime}$ curve and the $R R^{\prime}$ curves cross only once in the interval $] 0 ;+\infty[$. 
The equilibrium education level is then determined by:

$$
e^{*}=e_{P}\left(M^{*}\right)
$$

Figure 3 shows the best response functions of the poor country $\left(P P^{\prime}\right.$ curve $)$ and of the rich country ( $R R^{\prime}$ curve). Point $A$ is the Cournot-Nash equilibrium.

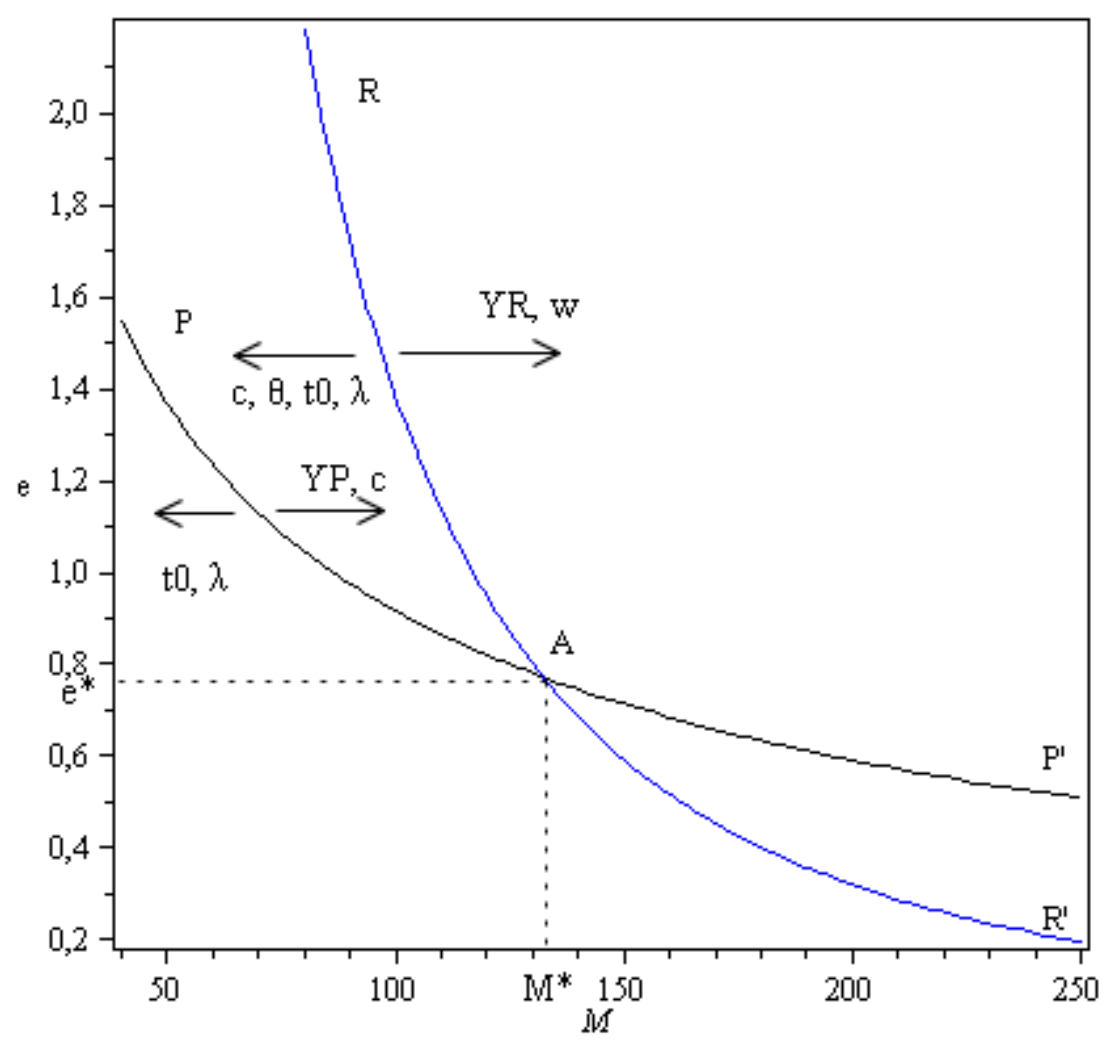

Figure 3: The Cournot-Nash equilibrium

We can also show that:

Proposition 4 The Cournot-Nash equilibrium of this game is dynamically stable.

Proof. We consider the sequence of adjustments where the poor country chooses $e_{t}$ given $M_{t-1}$, and the rich country chooses $M_{t}$ given $e_{t}$, and so on. ${ }^{6} \quad$ The equilibrium is dynamically stable if starting from any outside point $(e, M)$, the system converges toward the equilibrium solution $\left(e^{*}, M^{*}\right)$. The stability condition is $e_{R}(M)>e_{P}(M) \forall M<M^{*}$, and $e_{R}(M)<e_{P}(M) \forall M>M^{*}$.

\footnotetext{
6 The rationale would not change if we allow for a delay in adjusting migration quotas as well.
} 
We know that $\left(\frac{e_{R}(M)}{e_{P}(M)}\right)^{2}=\frac{1}{c}\left(\frac{b}{\psi}\right)^{2} \frac{\left(0.5 t_{0}+\lambda M\right)^{2}}{\left[M\left(t_{0}+\lambda M\right)\right]^{3}}=\frac{J\left(M^{*}\right)}{J(M)}$. Since $J(M)$ is increasing in $M$, the stability condition is met.

\subsection{Comparative statics}

We recall the compact notations of the parameters: $\psi=\sqrt{2 F_{P}^{-1}\left(Y_{P}\right)}$ and $b=\left(2 Y_{R}\right)^{2}\left(\frac{w+c}{c \theta}\right)$.

Table 1 summarizes the equilibrium values for the main endogenous variables.

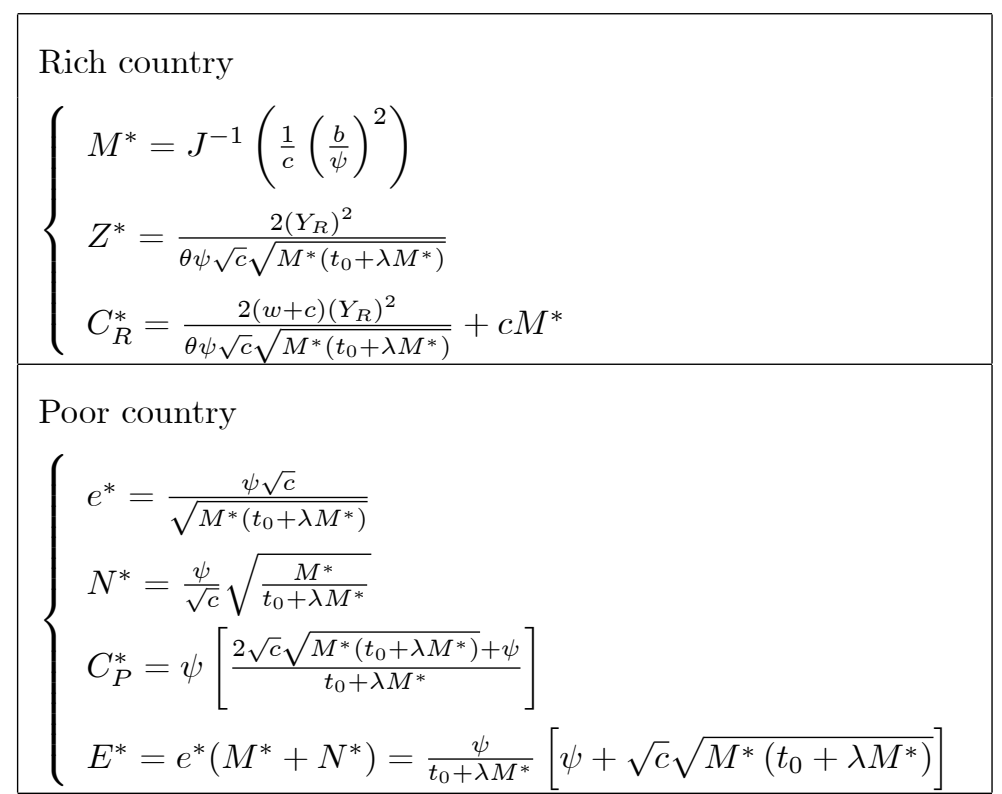

Table 1: Equilibrium values for both countries.

From Figure 3 or total differentiation of the equilibrium conditions, we can determine the impact of parameter changes on the following key variables: the number of migrants, the education level in the poor country, the number of skilled locals hired to produce the public service in the poor country, and the number of skilled locals hired in the rich country (see Appendix). Table 2 summarizes the main findings.

\begin{tabular}{|l|l|l|l|l|l|l|l|}
\hline & $\theta$ & $w$ & $c$ & $t_{0}$ & $\lambda$ & $Y_{P}$ & $Y_{R}$ \\
\hline$M^{*}$ & - & + & - & - & $-/+$ & - & + \\
\hline$e^{*}$ & + & - & + & - & - & + & - \\
\hline$N^{*}$ & - & + & - & - & - & $?$ & + \\
\hline$Z^{*}$ & $?$ & - & $?$ & - & - & $?$ & $?$ \\
\hline
\end{tabular}

Table 2: Comparative statics. 
Note that the local effect of the sensitivity of talent to migration opportunities $(\lambda)$ on the equilibrium number of migrants $\left(M^{*}\right)$ is : $\frac{d M^{*}}{d \lambda}=\frac{\left(0.5 t_{0}-\lambda M^{*}\right)\left(M^{*}\right)^{2}}{4\left(\lambda M^{*}\right)^{2}+4 t_{0} \lambda M^{*}+1.5\left(t_{0}\right)^{2}}$ (see Appendix). Thus the equilibrium number of migrants $M^{*}$ increases with $\lambda$ if and only if $\lambda M^{*}<0.5 t_{0}$, i.e. when the incentive effect of migration is not "too high"; in the opposite case, $M^{*}$ decreases with $\lambda$.

Some variations in parameters can be related to global trends and policy changes.

- For instance, if a poor country is developing, it is very probable that the need for public services will increase, that is $d Y_{P}>0$. As expected, the education level per civil servant would then increase. However, in equilibrium, the number of migrants would decrease, which, to some extent, would reduce workers' human capital, and would require a stronger education per worker.

- After a financial crisis such as the 2007-2009 Great Recession, a higher cost of physical capital per worker $(c)$ would raise the education level in the poor country, because the poor country would like to hire less people but better trained. Yet, since in the rich country the relative price of people trained at home compared to migrants $(\sigma)$ declines, the rich country would host less migrants. The human capital of migrants would further decline, and reinforce the need to raise the education level in the poor country.

As is often the case with non-cooperative equilibria, when decision makers play "one against the other", the outcome is Pareto-inefficient. In other words, should they negotiate on the key decision variables (in our case, $e$ and $M$ ), the resulting cooperative equilibrium would bring about an improvement in welfare for both parties.

The next section investigates this cooperative equilibrium. In particular, we would like to know in what direction endogenous variable move when we go from the non-cooperative to the cooperative equilibrium. The analysis will emphasize the key role of the sector-specific brain gain effect: the type of the cooperative equilibrium depends to a large extent on the sensitivity of talent to migration (as captured by our parameter $\lambda$ ). 


\section{The cooperative equilibrium}

Starting from the Cournot-Nash equilibrium, the two countries might strive to work out a Paretoefficient allocation of resources by bargaining about migration to the rich country and education in the poor country. Let us denote by $C_{P}^{*}$ and $C_{R}^{*}$ the investment costs in the poor (respectively rich) country as evaluated at the Nash equilibrium values $e^{*}$ and $M^{*}$ (see Table 2), and let us assume that should the negotiations fail, the non-cooperative solution prevails. In this case, the Nash solution to the negotiation problem would be obtained by maximizing the product of each country's net gain of cooperating raised respectively to the power $\rho$ and $(1-\rho)$, with $\rho \in[0,1]$ being representative of the relative bargaining power: ${ }^{7}$

$$
\left\{\begin{array}{l}
\max _{e, M}\left\{[c N+e(M+N)]-C_{P}^{*}\right\}^{1-\rho}\left\{[(w+c) Z+c M]-C_{R}^{*}\right\}^{\rho} \\
\text { with: } Y_{P}=F_{P}(N q) \\
\text { with: } Y_{R}=F_{R}(Z \theta, M q) \\
\text { with: } q=0.5\left(t_{0}+\lambda M\right) e
\end{array}\right.
$$

The solution will be denoted by $(\hat{e}, \hat{M})$. It is difficult to solve this non-linear problem and find an explicit solution. One way to circumvent the analytical complexity of this problem is to focus on the isocost curves; this approach will allow us to provide a graphic solution.

\subsection{Poor country isocost curves}

According to Equation (8) which takes into account the production target constraint in the poor country, the total investment cost in physical and human capital can be written as a function in $e$ and $M: C_{P}(e, M)=\frac{(c+e)}{e} \frac{\psi^{2}}{\left(t_{0}+\lambda M\right)}+e M$.

An isocost curve is made of all pairs $(e, M)$ verifying condition: $C_{P}(e, M)=c t$. The shape of such isocost curves can be inferred from analyzing the derivative $\left[\frac{d M}{d e}\right]_{C_{P}=c t}$. Total differentiation of the isocost condition leads to:

$$
\left[\frac{d M}{d e}\right]_{C_{P}=c t}=\frac{M-\frac{c}{e^{2}} \frac{\psi^{2}}{\left(t_{0}+\lambda M\right)}}{\frac{(c+e)}{e} \frac{\psi^{2}}{\left(t_{0}+\lambda M\right)^{2}} \lambda-e} .
$$

Notice that $\left[\frac{d M}{d e}\right]_{C P=c t}=0$ implies $M=\frac{c}{e^{2}} \frac{\psi^{2}}{\left(t_{0}+\lambda M\right)}$ or $e=\sqrt{\frac{c \psi^{2}}{M\left(t_{0}+\lambda M\right)}}=e_{P}(M)$. In other words,

\footnotetext{
7 In an extreme but plausible case, the rich country has all the power, $\rho=1$.
} 
if the isocost curve is represented in the referential $(O e, O M)$, we know that the curve will have a zero slope right on the best response function of the poor country. In the opposite referential $(O M, O e)$, the slope of the isocost curve is infinite, i.e., the curve is tangent to a vertical line at the crossing point with the best response function.

We are interested in the sign of the denominator of expression (33) in the neighborhood of $e_{P}(M)$. Replacing $e$ by $e_{P}(M)$, we can show (after some calculations) that the sign depends in a critical manner on the strength of the brain gain effect:

$$
\frac{\left(c+e_{P}(M)\right)}{e_{P}(M)} \frac{\psi^{2}}{\left(t_{0}+\lambda M\right)^{2}} \lambda-e_{P}(M) \gtrless 0 \Leftrightarrow \lambda \gtrless \frac{c}{e_{P}(M)} \frac{t_{0}}{M} .
$$

In particular, these inequalities hold for the Cournot-Nash equilibrium values $\left(e^{*}, M^{*}\right)$ which also depend on $\lambda .{ }^{8} \quad$ So, equation:

$$
\lambda=\frac{c}{e^{*}(\lambda)} \frac{t_{0}}{M^{*}(\lambda)}
$$

implicitly defines a fixed point $\lambda_{0}>0$ such that:

- For a weak (or inexistent) sector-specific brain gain effect $\left(0 \leq \lambda<\lambda_{0}\right)$, in the neighborhood of $\left(e^{*}, M^{*}\right)$ we have $\left[\frac{d M}{d e}\right]_{C_{P}=c t}>0$ for $e<e^{*}$, and $\left[\frac{d M}{d e}\right]_{C_{P}=c t}<0$ for $e>e^{*}$.

- For a strong sector-specific brain gain effect $\left(\lambda>\lambda_{0}\right)$, in the neighborhood of $\left(e^{*}, M^{*}\right)$ we have $\left[\frac{d M}{d e}\right]_{C_{P}=c t}>0$ for $e>e^{*}$, and $\left[\frac{d M}{d e}\right]_{C_{P}=c t}<0$ for $e<e^{*}$.

In order to draw correct families of isocost curves, we use a numerical simulation. ${ }^{9}$ We use the same $(O M, O e)$ referential as for the non-cooperative equilibrium. Figure 4 represents a family of isocost curves obtained for a small $\lambda(\lambda=0.005)$, Figure 5 represents a family of isocost curves obtained in the case of a larger $\lambda(\lambda=0.05)$. On both graphs we also represent the curve $P P^{\prime}$, i.e. the best response function of the poor country in the non-cooperative equilibrium. As it can be seen, isocost curves present an infinite slope (they are tangent to a vertical line) at points where they cross the best response function. But they have a "D form" in the first case, and a "reverse D form" in the second case.

\footnotetext{
${ }^{8}$ By definition of the non-cooperative equilibrium, $e^{*}=e_{P}\left(M^{*}\right)$.

${ }^{9}$ Parameter values are: $F^{-1}\left(Y_{P}\right)=105, Y_{R}=120, t=2, c=1, \theta=4, w=3$.
} 


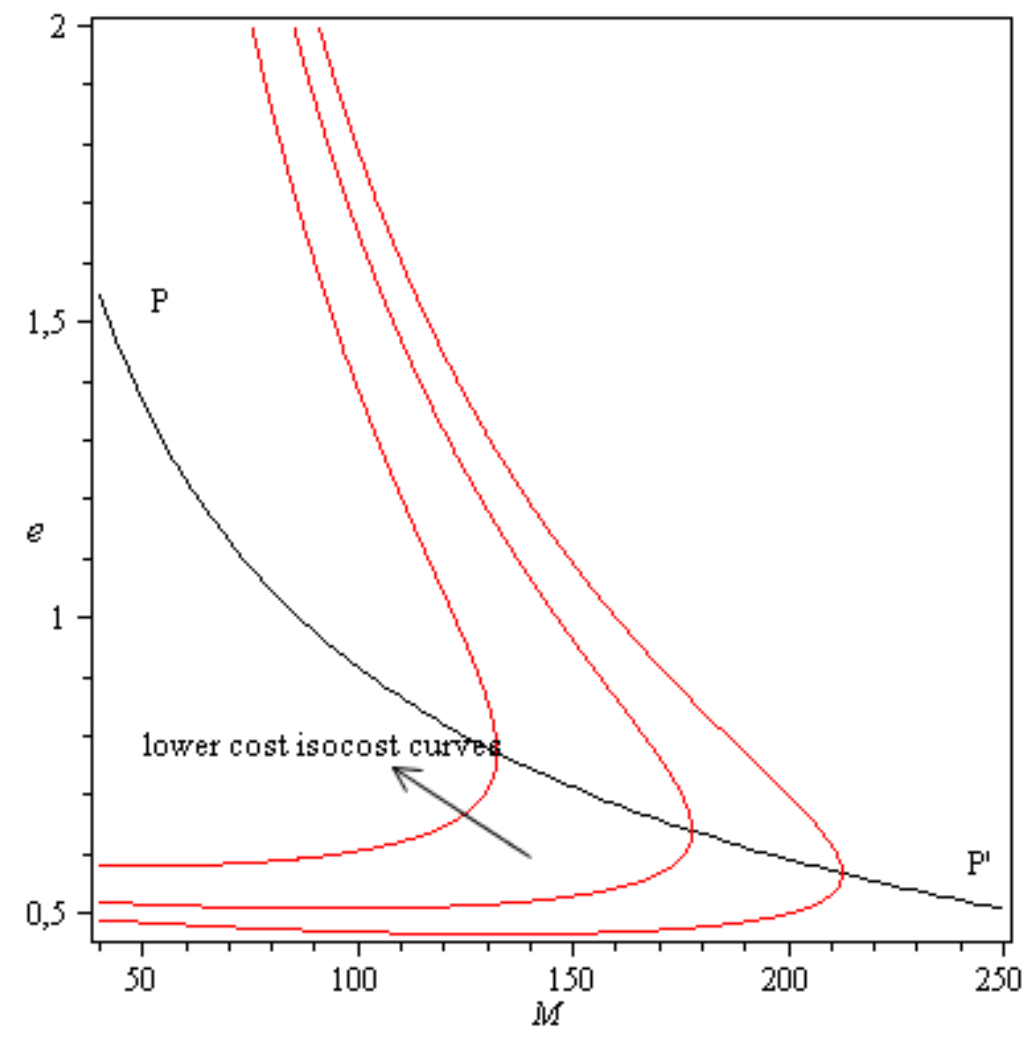

Figure 4: Poor country isocost curves - small brain gain effect

In case of a small brain gain effect, isocost curves located toward the NW correspond to lower investment costs for the poor country.

In case of a strong brain gain effect, isocost curves located toward the SE correspond to lower investment costs for the poor country.

\subsection{Rich country isocost curves}

In the same way, the total investment cost in physical and human capital in the rich country can be written as a function of $e$ and $M$.

First, according to Equation (16) which takes into account the target production condition and the definition of $q$, we can write $Z$ as a function of $M$ and $e: Z=\frac{\left(Y_{R}\right)^{2}}{0.5 \theta M\left(t_{0}+\lambda M\right) e}$.

The investment cost of producing $Y_{R}$ can thus be written:

$$
C_{R}(e, M)=\frac{2\left(Y_{R}\right)^{2}(w+c)}{\theta e M\left(t_{0}+\lambda M\right)}+c M
$$




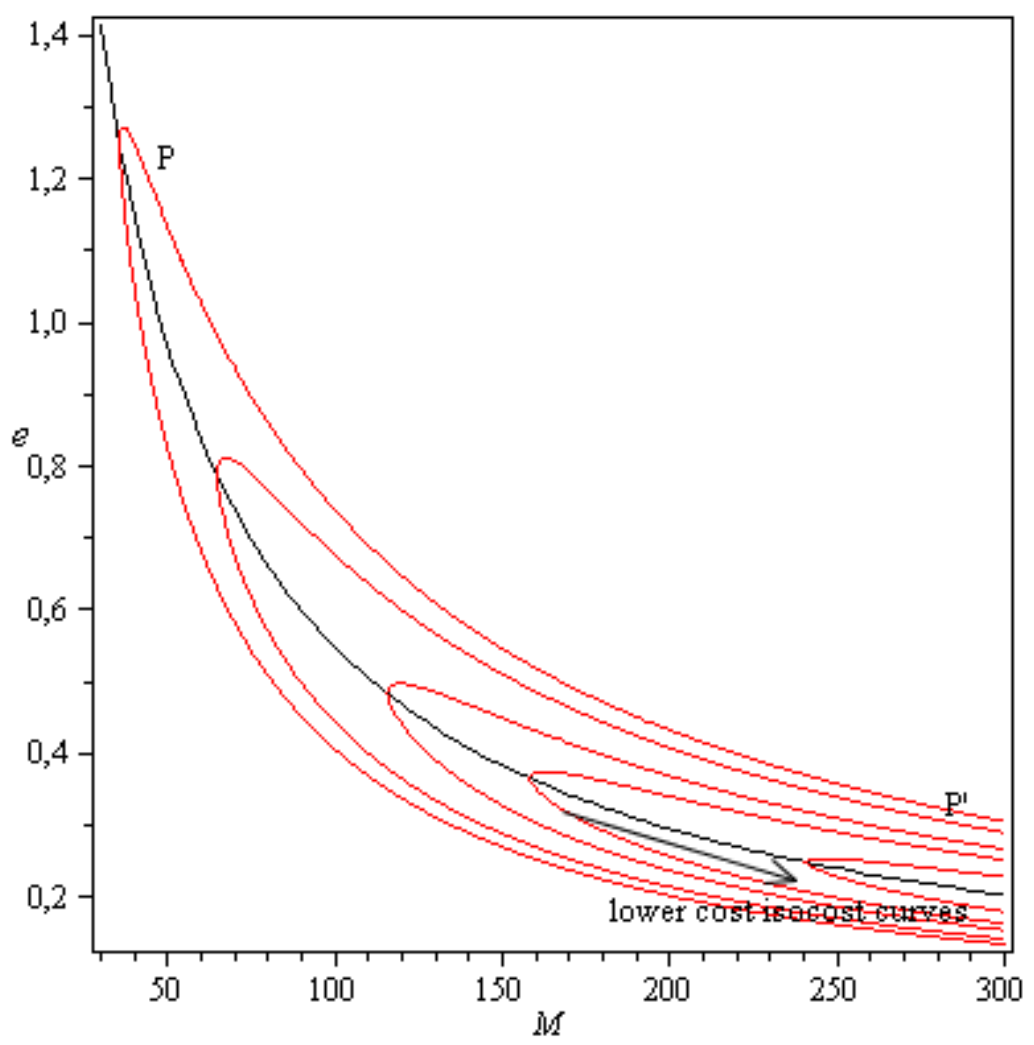

Figure 5: Poor country isocost curves - strong brain gain effect

Isocost curves are defined by: $C_{R}(e, M)=c t$. Total differentiation leads to:

$$
\left[\frac{d e}{d M}\right]_{C_{R}=c t}=\frac{c-\frac{2\left(Y_{R}\right)^{2}(w+c)}{\theta e} \frac{\left(t_{0}+2 \lambda M\right)}{M^{2}\left(t_{0}+\lambda M\right)^{2}}}{\frac{2\left(Y_{R}\right)^{2}(w+c)}{\theta e^{2}} \frac{1}{M\left(t_{0}+\lambda M\right)}}
$$

The isocost curve has a zero slope right for $M=M_{R}(e)=G^{-1}\left(\frac{b}{e}\right)$ as defined in the previous section. Furthermore, since $G(M)$ is increasing in $M$, we can show that $\left[\frac{d e}{d M}\right]_{C_{R}=c t}>0$ for $G(M)>\frac{b}{e} \Leftrightarrow M>M_{R}(e)$; and $\left[\frac{d e}{d M}\right]_{C_{R}=c t}<0$ for $G(M)<\frac{b}{e} \Leftrightarrow M<M_{R}(e)$.

In other words, rich country isocost curves have a U-shape in the referential $(O M, O e)$, with the troughs on the best-response function of the rich country. In Figure 6 we represent the $R R^{\prime}$ best response curve of the rich country and a family of isocost curves.

Isocost curves located toward the North of the $(O M, O e)$ plane correspond to lower investment costs. 


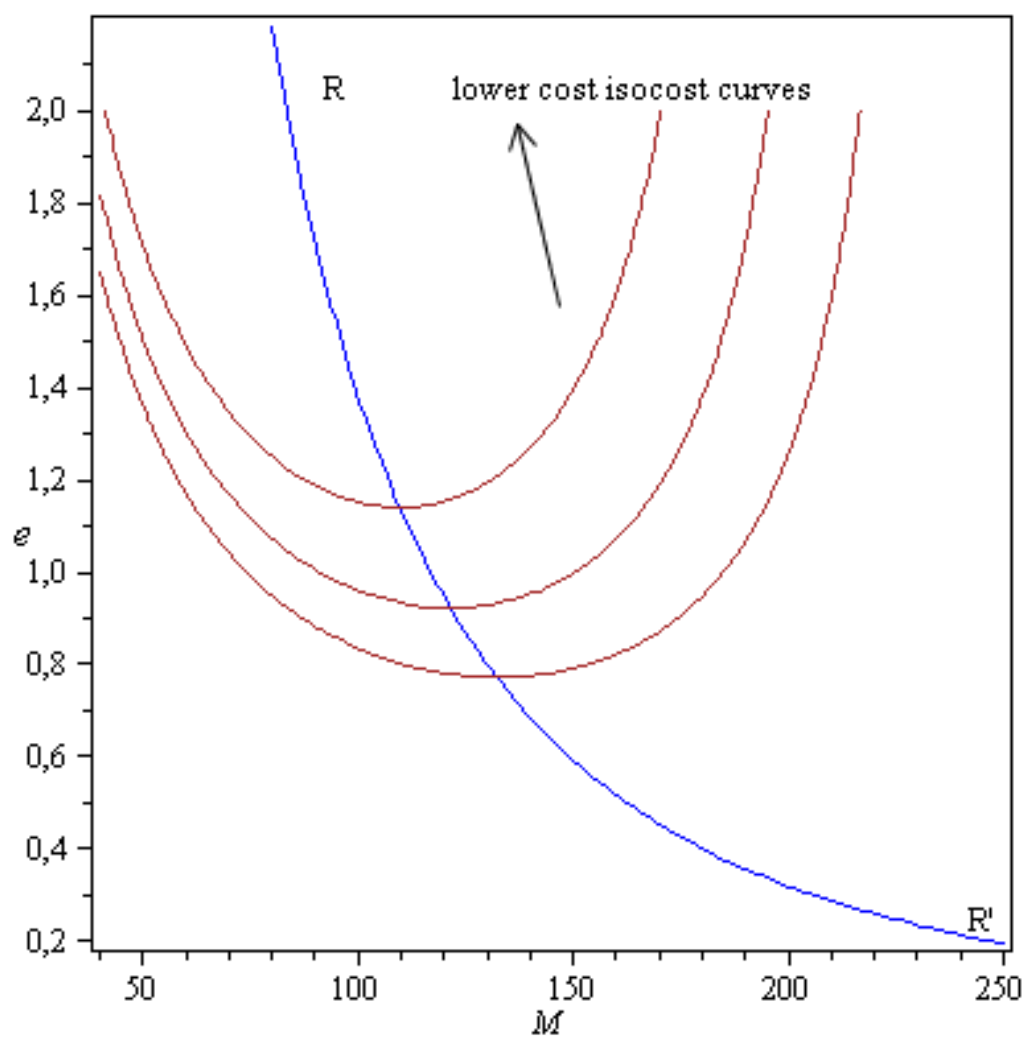

Figure 6: Rich country isocost curves

\subsection{Two types of cooperative equilibria}

As shown before, the form of the isocost curves of the poor country depends on the strength of the sector-specific brain gain effect (as captured by $\lambda$ ). As a consequence, we have two types of cooperative equilibria, depending on this key parameter.

As it will be shown, in our model, there is no structural difference between the extreme zero impact assumption and the positive but moderate brain gain assumption. A structural difference can be revealed in the case of a strong brain gain effect.

\subsubsection{Cooperative equilibrium: the case of a weak (or inexistent) brain gain effect}

Figure 7 displays the non-cooperative equilibrium $\mathrm{A}\left(e^{*}, M^{*}\right)$ at the crossing point between the two best response functions, and the two isocost curves, one for the poor country and another for the rich country, that correspond to the constant investment $\operatorname{cost} C_{P}^{*}$ and respectively $C_{R}^{*}$.

Whatever the cooperative equilibrium $(\hat{e}, \hat{M})$, we know that it will be located in the region between the two isocost curves, thus would require higher education for (all) locals in the poor 


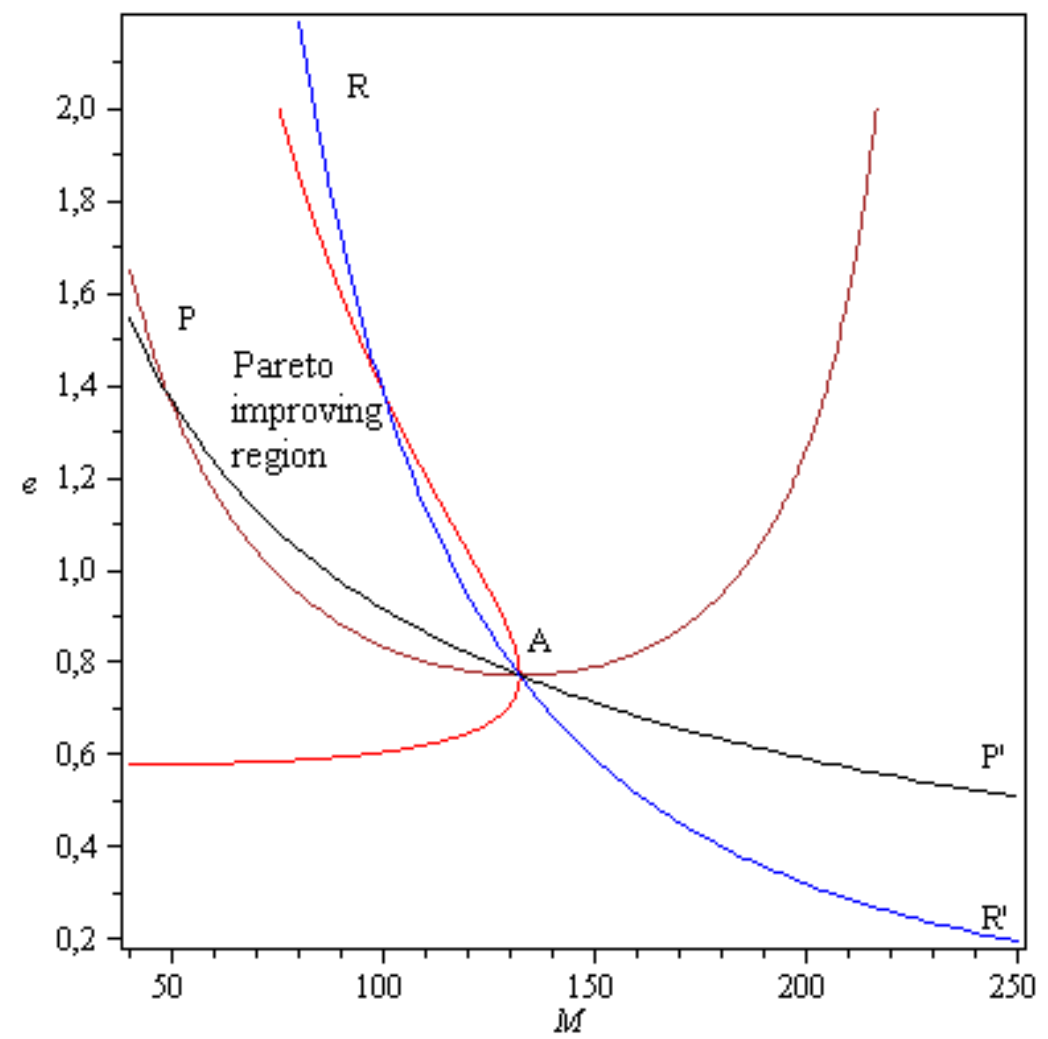

Figure 7: The region of the cooperative equilibrium - Small brain gain effect

country, and less migration (reduced migration quotas in the rich country). The Pareto-improving area is quite large.

Proposition 5 In the case of a relatively small (or inexistent) brain gain effect, without coordination the poor country tends to under-invest in education, and the rich country tends to hire too many migrants.

Proof. Cf. graphic analysis of the cooperative solution.

The region of Pareto-efficent contracts is made up of the locus where the isocost curves of the two countries are tangent (i.e., have the same slope) : $\left[\frac{d e}{d M}\right]_{C_{R}=c t}=\left[\frac{d e}{d M}\right]_{C_{P}=c t}$.

How the gain of moving from the non-cooperative to the cooperative equilibrium is split between the two countries depends on their relative negotiation power. If the rich country has the whole negotiation power, the equilibrium solution will be the point where the highest isocost curve of the rich country is tangent to the isocost curve $C_{P}(e, M)=C_{P}^{*}$ of the poor country; this requires very high education per capita. If we move toward the center of the cooperative region and the equal split of the gains from cooperation, the required education level is smaller. The number 
of migrants is less sensitive to the negotiation power.

\subsubsection{Cooperative equilibrium: the case of a strong brain gain effect}

In the opposite case of a strong brain gain effect, the isocost curves of the poor country have the opposite shape. Figure 8 shows non-cooperative equilibrium $\left(e^{*}, M^{*}\right)$ at point $\mathrm{A}$ and the two isocost curves that correspond to this equilibrium education and migration levels.

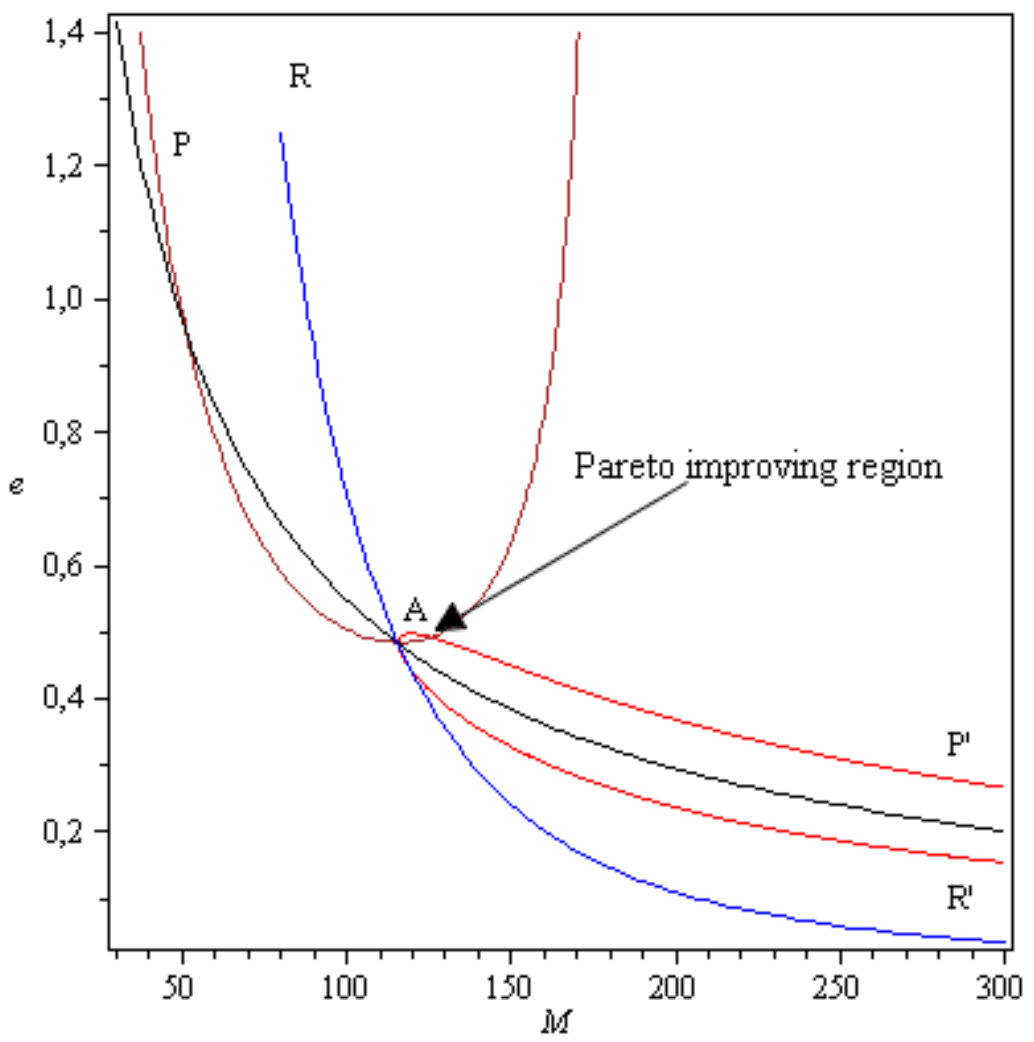

Figure 8: The region of the cooperative equilibrium - Large brain gain effect

This time the Pareto ameliorating region has a narrow, closed shape (it was quite large in the "small brain gain" case). In other words, gains from cooperation can only be modest. We can however notice that:

Proposition 6 In the case of a relatively large brain gain effect, without coordination the poor country tends to under-invest in education, and the rich country tends to impose too much restrictions on migration.

Proof. Cf. graphic analysis of the cooperative solution.

From the analysis of the two cases, we can infer without ambiguity that in a non-cooperative 
setting, poor countries tend to under-invest in education of their civil servants (doctors, teachers, researchers, etc.) - whatever the strength of the brain gain effect. Thus, we reach the same conclusion as Djajić et al. (2012), using a model that builds on a different transmission mechanism.

\section{Conclusion}

This paper has developed an original model of skilled migration, where migrants education is supplied for free by the government of the migrants' origin country. Such a framework is most relevant to analyze the migration of civil servants with high cross-border mobility and transferable skills such as doctors, nurses, teachers, researchers, etc. As the migration literature has pointed out, brain drain in such "strategic occupations" could be extremely harmful for developing countries. This provides substantial motivation for researchers to analyze the various policy transmission mechanisms and welfare implications.

In our model, governments in both source and host countries aim at delivering a predetermined amount of civil services, at the lowest investment cost. The problem is analyzed as a game between the poor country that decides on the education level of the civil servants and the rich country that decides how many such migrants it wants to host. The model takes into account the potentially favorable impact of migration on attracting highly talented people towards that profession, what we have defined as the sector-specific brain gain effect. Despite the relatively high analytical complexity of the problem, the paper presents a neat solution with positive migration and positive investment in education. It can be shown that the equilibrium is unique and stable, and comparative statics allow to comment on possible trends in migration; in particular, in this model, economic growth in poor countries would bring about less migration and additional education per worker.

We then analyze the cooperative equilibrium, where the two countries can negotiate on the Pareto-efficient education-migration bundle. We show that the nature of the cooperative equilibrium depends to a large extent on the strength of the sector-specific brain gain effect. When the sensitivity of talent to migration opportunities is relatively small (not different from the case where the effect does not exist at all), in the non-cooperative equilibrium the poor country tends 
to invest too little in education, and the rich country tends to attract too many migrants. In the opposite case of a strong brain gain effect, the poor country still neglects education, while the rich country does not host enough migrants.

The welfare gains to be reaped when moving from a non-cooperative to a cooperative organization of international relationships on migration also depend to a large extent on the strength of the brain gain effect. These gains can be quite large if the brain gain effect is small or zero, they might be quite modest in the case of a large brain gain effect. In a pragmatic approach to policy making, as long as empirical studies on this specific form of brain gain did not reach a definitive conclusion, common sense would favour the cooperative solution; there is nothing to lose in one case, but a large expected gain in the other case.

In this paper we focused on the case where each country uses its own national resources to fund the public provision of tertiary education. However, as mentioned before, developed countries tend to finance part of the tertiary education provided by developing countries through the official development aid (and part of that aid is used by developed countries to educate students from developing countries in their own universities). This is one important limitation of our analysis. Future research might study the optimal education transfer policy from richer to poorer countries.

\section{References}

Batista, Catia, Aitor Lacuesta and Pedro C. Vicente, 2012, Testing the 'brain gain' hypothesis: Micro evidence from Cape Verde. Journal of Development Economics, 97, 1, pp. $32-45$.

Beine, Michel, Frédéric Docquier and Çaglar Özden, 2011, Diasporas. Journal of Development Economics, 95, 1, pp. 30-41.

Beine, Michel, Frédéric Docquier and Cecily Oden-Defoort, 2011, A panel data analysis of the brain gain. World Development, 39, 4, pp. 523-532

Beine, Michel, Frédéric Docquier and Hillel Rapoport, 2001, Brain drain and economic growth: Theory and evidence. Journal of Development Economics, 64, 1, pp. 275-89.

Beine, Michel, Frédéric Docquier and Hillel Rapoport, 2008, Brain drain and human capital formation in developing countries: Winners and losers. Economic Journal, 118, pp. 631-652.

Belot, Michele V. K. and Timothy J. Hatton, 2012, Immigrant selection in the OECD. Scandinavian Journal of Economics, 114, pp. 1105-1128.

Borjas, George J., 1987, Self-selection and the earnings of immigrants. American Economic Review, 77, 4, pp. 531-533. 
Chand, Satish and Michael A. Clemens, 2008, Skilled emigration and skill creation: A Quasiexperiment. Center for Global Development Working Paper 152.

Chiquiar, Daniel and Gordon H. Hanson, 2005, International migration, self-selection, and the distribution of wages: Evidence from Mexico and the United States. Journal of Political Economy, 113, 2, pp. 239-281.

Cortes, Patricia and Jessica Pan, 2012, Relative quality of foreign nurses in the United States. Working Paper presented at the 5th International Conference on Migration and Development, June 2012, Paris.

Djajić, Slobodan, Michael S. Michael and Alexandra Vinogradova, 2012, Migration of skilled workers: Policy interaction between host and source countries. Journal of Public Economics, 96, 11-12, pp. 1015-1024.

Docquier, Frédéric, Ousmane Faye and Pierre Pestieau, 2008, Is migration a good substitute for education subsidies?. Journal of Development Economics, 86, pp. 263-276.

Docquier, Frédéric, Olivier Lohest and Abdeslam Marfouk, 2007, Brain drain in developing countries. World Bank Economic Review, 21, 2, pp. 193-218.

Docquier, Frédéric, Lindsay B. Lowell and Abdeslam Marfouk, 2009, A gendered assessment of highly skilled emigration. Population and Development Review, 35, 2, pp. 297-321.

Docquier, Frédéric and Hillel Rapoport, 2012, Globalization, brain drain, and development. Journal of Economic Literature, 50, 3, pp. 681-730. http://dx.doi.org/10.1257/jel.50.3.681

Eurydice, 2011, Modernisayion of Higher Education in Europe: Funding and the Social Dimension. Education, Audiovisual and Culture Executive Agency (EACEA P9 Eurydice), Brussels.

Gibson, John and David McKenzie, 2011, The microeconomic determinants of emigration and return migration of the best and brightest: Evidence from the Pacific. Journal of Development Economics, 95, 1, pp. 18-29.

Grogger, Jeffrey and Gordon H. Hanson, 2011, Income maximization and the selection and sorting of international migrants. Journal of Development Economics, 95, 1, pp. 42-57.

IOM, 2011, International Organization for Migration website, http://www.iom.int/jahia/Jahia/about-migration/lang/en.

McKenzie, David, Steven Stillman and John Gibson, 2010, How important is selection? Experimental vs. non-experimental measures of the income gains from migration. Journal of the European Economic Association, 8, 4, pp. 913-945.

Mountford, Andrew, 1997, Can a brain drain be good for growth in the source economy? Journal of Development Economics, 53, 2, pp. 287-303.

OECD. 2012. Education at a Glance 2012: OECD Indicators. OECD Publishing. http://dx.doi.org/10.1787/eag-2012-en.

Ortega, Francesc and Giovanni Peri, 2009, The causes and effects of international migrations: Evidence from OECD countries 1980-2005. University of California at Davis Department of Economics Working Paper 09-6.

Poutvaara, Panu, 2008, Public and private education in an integrated Europe: Studying to migrate and teaching to stay?. Scandinavian Journal of Economics, 110, 3, pp. 591-608.

Ratha, Dilip, Sanket Mohapatra and Ani Silwal, 2011, Migration and Remittances Factbook 2011. Migration and Remittances Unit, World Bank (Eds.), Washington D.C. http://go.worldbank.org/QGUCPJTOR0. 
Roy, A. D., 1951, Some thought on the distribution of earnings. Oxford Economic Papers, 3, pp. 135-146.

Solow, Robert M., 1979, Another possible source of wage stickiness. Journal of Macroeconomics, 1, 1, pp. 79-82.

Stark, Oded, Christian Helmenstein and Alexia Prskawetz, 1997, A brain gain with a brain drain. Economic Letters, 55, pp. 227-234.

Stark, Oded, Christian Helmenstein and Alexia Prskawetz, 1998, Human capital depletion, human capital formation, and migration: A blessing or a "curse"?. Economic Letters, 60, pp. 363-367.

Stark, Oded and Yong Wang, 2002, Inducing human capital formation: migration as a substitute for subsidies. Journal of Public Economics, 86, pp. 29-46.

Stark, Oded, 2005, The new economics of the brain gain. World Economics, 6, 2, pp. 137-140

Stark, Oded and Agnieszka Dorn, 2012, International migration, human capital formation, and savings. Economic Letters, forthcoming.

World Bank, 2010, Financing Higher Education in Africa. The World Bank, Washington, D.C.

\section{A Appendix. Comparative statics calculations}

\section{A.1 The main equilibrium equations}

By totally differentiating the equilibrium condition

$$
\begin{aligned}
J\left(M^{*}\right) & =\frac{1}{c}\left(\frac{b}{\psi}\right)^{2} \\
\frac{\left[M^{*}\left(t_{0}+\lambda M^{*}\right)\right]^{3}}{\left(0.5 t_{0}+\lambda M^{*}\right)^{2}} & =\left(2 Y_{R}\right)^{4}\left(\frac{1}{\psi}\right)^{2} \frac{(w+c)^{2}}{\theta^{2} c^{3}}
\end{aligned}
$$

we get:

$$
\begin{aligned}
& \Sigma\left\{\left[4\left(\lambda M^{*}\right)^{2}+4 t_{0} \lambda M^{*}+1.5\left(t_{0}\right)^{2}\right] d M^{*}+\left(0.5 t_{0}+2 \lambda M^{*}\right) M^{*} d t_{0}+\left(\lambda M^{*}-0.5 t_{0}\right)\left(M^{*}\right)^{2} d \lambda\right\} \\
= & \Pi\left[-\frac{2}{\psi} d \psi+\frac{4}{Y_{R}} d Y_{R}-\frac{2}{\theta} d \theta+\frac{2}{w+c} d w-\frac{3 w+c}{c(w+c)} d c\right]
\end{aligned}
$$

with $\Sigma=\frac{\left[M^{*}\left(t_{0}+\lambda M^{*}\right)\right]^{2}}{\left(0.5 t_{0}+\lambda M^{*}\right)^{3}}$ and $\Pi=\frac{1}{c}\left(\frac{b}{\psi}\right)^{2}=\left(2 Y_{R}\right)^{4}\left(\frac{1}{\psi}\right)^{2} \frac{(w+c)^{2}}{\theta^{2} c^{3}}$.

Differentiating condition $e^{*}=\psi \sqrt{c}\left[M^{*}\left(t_{0}+\lambda M^{*}\right)\right]^{-1 / 2}$, we get:

$d e^{*}=\frac{1}{\sqrt{c} \sqrt{M^{*}\left(t_{0}+\lambda M^{*}\right)}}\left\{c d \psi+0.5 \psi d c-\frac{0.5 \psi c}{M^{*}\left(t_{0}+\lambda M^{*}\right)}\left[M^{*} d t_{0}+\left(M^{*}\right)^{2} d \lambda+\left(t_{0}+2 \lambda M^{*}\right) d M^{*}\right]\right\}$ 
Differentiating the equilibrium value of $N^{*}=\frac{\psi}{\sqrt{c}} \sqrt{\frac{M^{*}}{t_{0}+\lambda M^{*}}}$, we get:

$$
\begin{aligned}
d N^{*}= & \sqrt{\frac{M^{*}}{c\left(t_{0}+\lambda M^{*}\right)}} d \psi \\
& +\frac{0.5 \psi}{\left[c\left(t_{0}+\lambda M^{*}\right)\right]^{2}} \sqrt{\frac{c\left(t_{0}+\lambda M^{*}\right)}{M^{*}}}\left\{c\left[t_{0} d M^{*}-M^{*} d t_{0}-\left(M^{*}\right)^{2} d \lambda\right]-M^{*}\left(t_{0}+\lambda M\left({ }^{*} A d k 2\right\}\right.\right.
\end{aligned}
$$

Finally, differentiating the equilibrium value of $Z^{*}=\frac{2\left(Y_{R}\right)^{2}}{\theta \psi \sqrt{c} \sqrt{M^{*}\left(t_{0}+\lambda M^{*}\right)}}$, we get:

$$
\begin{aligned}
d Z^{*}= & \frac{Y_{R}}{[\theta \psi]^{2} \sqrt{c} \sqrt{M^{*}\left(t_{0}+\lambda M^{*}\right)}}\left\{4 \theta \psi d Y_{R}-Y_{R}\left[2 \psi d \theta+2 \theta d \psi+\frac{\theta \psi}{c} d c\right]\right\} \\
& -\frac{\left(Y_{R}\right)^{2}}{\theta \psi \sqrt{c}\left[M^{*}\left(t_{0}+\lambda M^{*}\right)\right]^{3 / 2}}\left[M^{*} d t_{0}+\left(M^{*}\right)^{2} d \lambda+\left(t_{0}+2 \lambda M^{*}\right) d M^{*}\right]
\end{aligned}
$$

\begin{tabular}{|c|c|c|}
\hline of: & with respect to: $\theta$ & with respect to: $w$ \\
\hline$M^{*}$ & $-\frac{2}{J^{\prime}\left(M^{*}\right)} \frac{\left(2 Y_{R}\right)^{4}(w+c)^{2}}{\psi^{2}(\theta c)^{3}}<0$ & $\frac{2}{J^{\prime}\left(M^{*}\right)} \frac{\left(2 Y_{R}\right)^{4}}{(\theta \psi)^{2}} \frac{(w+c)}{c^{3}}>0$ \\
\hline$e^{*}$ & $-\frac{0.5 \psi \sqrt{c}\left(t_{0}+2 \lambda M^{*}\right)}{\left[M^{*}\left(t_{0}+\lambda M^{*}\right)\right]^{3 / 2}} \frac{d M^{*}}{d \theta}>0$ & $-\frac{0.5 \psi \sqrt{c}\left(t_{0}+2 \lambda M^{*}\right)}{\left[M^{*}\left(t_{0}+\lambda M^{*}\right)\right]^{3 / 2}} \frac{d M^{*}}{d w}<0$ \\
\hline$N^{*}$ & $\frac{0.5 \psi c t_{0}}{\left[c\left(t_{0}+\lambda M^{*}\right)\right]^{2}} \sqrt{\frac{c\left(t_{0}+\lambda M^{*}\right)}{M^{*}}} \frac{d M^{*}}{d \theta}<0$ & $\frac{0.5 \psi c t_{0}}{\left[c\left(t_{0}+\lambda M^{*}\right)\right]^{2}} \sqrt{\frac{c\left(t_{0}+\lambda M^{*}\right)}{M^{*}}} \frac{d M^{*}}{d w}>0$ \\
\hline$Z^{*}$ & $-\frac{\left(Y_{R}\right)^{2}}{\theta \psi \sqrt{c} \sqrt{M^{*}\left(t_{0}+\lambda M^{*}\right)}}\left\{\frac{2}{\theta}+\frac{\left(t_{0}+2 \lambda M^{*}\right)}{\sqrt{c} \sqrt{M^{*}\left(t_{0}+\lambda M^{*}\right)}} \frac{d M^{*}}{d \theta}\right.$ & $-\frac{\left(Y_{R}\right)^{2}\left(t_{0}+2 \lambda M^{*}\right)}{\theta \psi \sqrt{c}\left[M^{*}\left(t_{0}+\lambda M^{*}\right)\right]^{3 / 2}} \frac{d M^{*}}{d w}<0$ \\
\hline
\end{tabular}

\section{A.2 Partial derivatives of equilibrium values (Table 2)}

\begin{tabular}{|l|l|}
\hline of: & with respect to: $c$ \\
\hline$M^{*}$ & $-\frac{\left(2 Y_{R}\right)^{4}}{\left(\psi \theta c^{2}\right)^{2}} \frac{(w+c)(3 w+c)}{J^{\prime}\left(M^{*}\right)}<0$ \\
\hline$e^{*}$ & $\frac{0.5 \psi}{\sqrt{c M^{*}\left(t_{0}+\lambda M^{*}\right)}}\left\{1-\frac{c\left(t_{0}+2 \lambda M^{*}\right)}{M^{*}\left(t_{0}+\lambda M^{*}\right)} \frac{d M^{*}}{d c}\right\}>0$ \\
\hline$N^{*}$ & $\frac{0.5 \psi}{\left[c\left(t_{0}+\lambda M^{*}\right)\right]^{2}} \sqrt{\frac{c\left(t_{0}+\lambda M^{*}\right)}{M^{*}}}\left\{c t_{0} \frac{d M^{*}}{d c}-M^{*}\left(t_{0}+\lambda M^{*}\right)\right\}<0$ \\
\hline$Z^{*}$ & $-\frac{\left(Y_{R}\right)^{2}}{\theta \psi \sqrt{c} \sqrt{M^{*}\left(t_{0}+\lambda M^{*}\right)}}\left\{\frac{1}{c}+\frac{\left(t_{0}+2 \lambda M^{*}\right)}{M^{*}\left(t_{0}+\lambda M^{*}\right)} \frac{d M^{*}}{d c}\right\}$ \\
\hline
\end{tabular}

\begin{tabular}{|l|l|}
\hline of: & with respect to: $t_{0}$ \\
\hline$M^{*}$ & $-\frac{\left(0.5 t_{0}+2 \lambda M^{*}\right) M^{*}}{4\left(\lambda M^{*}\right)^{2}+4 t_{0} \lambda M^{*}+1.5\left(t_{0}\right)^{2}}<0$ \\
\hline$e^{*}$ & $-\frac{0.5 \psi \sqrt{c}}{\sqrt{M^{*}\left(t_{0}+\lambda M^{*}\right)}}\left[\frac{t_{0}}{4\left(\lambda M^{*}\right)^{2}+4 t_{0} \lambda M^{*}+1.5\left(t_{0}\right)^{2}}\right]<0$ \\
\hline$N^{*}$ & $\frac{0.5 \psi c}{\left[c\left(t_{0}+\lambda M^{*}\right)\right]^{2}} \sqrt{\frac{c\left(t_{0}+\lambda M^{*}\right)}{M^{*}}}\left[t_{0} \frac{d M^{*}}{d t_{0}}-M^{*}\right]<0$ \\
\hline$Z^{*}$ & $-\frac{\left(Y_{R}\right)^{2} t_{0} M^{*}}{\theta \psi \sqrt{c}\left[M^{*}\left(t_{0}+\lambda M^{*}\right)\right]^{3 / 2}}\left[\frac{\lambda M^{*}+t_{0}}{4\left(\lambda M^{*}\right)^{2}+4 t_{0} \lambda M^{*}+1.5\left(t_{0}\right)^{2}}\right]<0$ \\
\hline
\end{tabular}




\begin{tabular}{|l|l|}
\hline of: & with respect to: $\lambda$ \\
\hline$M^{*}$ & $\frac{\left(0.5 t_{0}-\lambda M^{*}\right)\left(M^{*}\right)^{2}}{4\left(\lambda M^{*}\right)^{2}+4 t_{0} \lambda M^{*}+1.5\left(t_{0}\right)^{2}}$ \\
\hline$e^{*}$ & $-\frac{\psi \sqrt{c} \sqrt{M^{*}\left(t_{0}+\lambda M^{*}\right)}}{4\left(\lambda M^{*}\right)^{2}+4 t_{0} \lambda M^{*}+1.5\left(t_{0}\right)^{2}}<0$ \\
\hline$N^{*}$ & $-\frac{0.5 \psi c\left(M^{*}\right)^{2}}{\left[c\left(t_{0}+\lambda M^{*}\right)\right]^{2}} \sqrt{\frac{c\left(t_{0}+\lambda M^{*}\right)}{M^{*}}}\left[\frac{4\left(\lambda M^{*}\right)^{2}+5 t_{0} \lambda M^{*}+\left(t_{0}\right)^{2}}{4\left(\lambda M^{*}\right)^{2}+4 t_{0} \lambda M^{*}+1.5\left(t_{0}\right)^{2}}\right]<0$ \\
\hline$Z^{*}$ & $-\frac{2\left(Y_{R}\right)^{2} \sqrt{M^{*}\left(t_{0}+\lambda M^{*}\right)}}{\theta \psi \sqrt{c}\left[4\left(\lambda M^{*}\right)^{2}+4 t_{0} \lambda M^{*}+1.5\left(t_{0}\right)^{2}\right]}<0$ \\
\hline
\end{tabular}

\begin{tabular}{|l|l|l|}
\hline of: & with respect to: $\psi\left(\right.$ with $\left.\frac{d \psi}{d Y_{P}}=\frac{F_{P}^{-1}\left(Y_{P}\right)}{\sqrt{2 F_{P}^{-1}\left(Y_{P}\right)}}>0\right)$ & with respect to: $Y_{R}$ \\
\hline$M^{*}$ & $-\frac{2}{J^{\prime}\left(M^{*}\right)} \frac{\left(2 Y_{R}\right)^{4}(w+c)^{2}}{\psi^{3} \theta^{2} c^{3}}<0$ & $\frac{64\left(Y_{R}\right)^{3}}{J^{\prime}\left(M^{*}\right)} \frac{1}{\psi^{2}} \frac{(w+c)^{2}}{\theta^{2} c^{3}}>0$ \\
\hline$e^{*}$ & $\frac{\sqrt{c}}{\sqrt{M^{*}\left(t_{0}+\lambda M^{*}\right)}}\left\{1-\frac{0.5 \psi\left(t_{0}+2 \lambda M^{*}\right)}{M^{*}\left(t_{0}+\lambda M^{*}\right)} \frac{d M^{*}}{d \psi}\right\}>0$ & $-\frac{0.5 \psi \sqrt{c}\left(t_{0}+2 \lambda M^{*}\right)}{\left[M^{*}\left(t_{0}+\lambda M^{*}\right)\right]^{3 / 2}} \frac{d M^{*}}{d Y_{R}}<0$ \\
\hline$N^{*}$ & $\sqrt{\frac{M^{*}}{c\left(t_{0}+\lambda M^{*}\right)}}\left[1+\frac{0.5 \psi t_{0}}{M^{*}\left(t_{0}+\lambda M^{*}\right)} \frac{d M^{*}}{d \psi}\right]$ & $\frac{0.5 \psi c t_{0}}{\left[c\left(t_{0}+\lambda M^{*}\right)\right]^{2}} \sqrt{\frac{c\left(t_{0}+\lambda M^{*}\right)}{M^{*}}} \frac{d M^{*}}{d Y_{R}}>0$ \\
\hline$Z^{*}$ & $-\frac{\left(Y_{R}\right)^{2}}{\theta \psi \sqrt{c} \sqrt{M^{*}\left(t_{0}+\lambda M^{*}\right)}}\left\{\frac{2}{\psi}+\frac{\left(t_{0}+2 \lambda M^{*}\right)}{M^{*}\left(t_{0}+\lambda M^{*}\right)} \frac{d M^{*}}{d \psi}\right\}$ & $\frac{Y_{R}}{\theta \psi \sqrt{c} \sqrt{M^{*}\left(t_{0}+\lambda M^{*}\right)}}\left\{4 d Y_{R}-\frac{Y_{R}\left(t_{0}+2 \lambda M^{*}\right)}{M^{*}\left(t_{0}+\lambda M^{*}\right)} d M^{*}\right\}$ \\
\hline
\end{tabular}


ESSEC Business School Avenue Bernard Hirsch BP 50105

95021 Cergy-Pontoise Cedex

France

Tél. +33(0)134433000

$\mathrm{Fax}+33(0) 134433001$

www.essec.fr

\section{ESSEC Executive Education} CNIT BP 230

92053 Paris-La Défense France

Têl. +33(0)146924900

Fax +33(0)1 46924990

http://formation.essec.fr

ESSEC Business School

Singapore Campus

100 Victoria Street

National Library Building \# 13-02

Singapore 188064

essecasia@essec.fr

Tél. +6568849780

Fax +6568849781

www.essec.edu

Informations

Alison Bougi

+33 (0)134433358

bougi@essec.fr

www.essec.fr

research.center@essec.fr

ISSN 1291-9616 